\title{
Efficient lighting in buildings: The lack of legislation in Portugal
}

\author{
António Manuel Almeida ${ }^{\mathrm{a}, \mathrm{b}, *}$, António Gomes Martins ${ }^{\mathrm{a}, \mathrm{c}}$ \\ a INESC Coimbra, Rua Antero de Quental, 199, 3000-033 Coimbra, Portugal \\ ${ }^{\mathrm{b}}$ Instituto Superior de Engenharia de Coimbra, Rua Pedro Nunes, 3030-199 Coimbra, Portugal \\ ${ }^{\mathrm{c}}$ Universidade de Coimbra, Portugal
}

\section{H I G H L I G H T S}

- In the Portuguese legislation there are no rules concerning the use of daylight.

- Lack of specific regulation limiting power density of artificial lighting.

- Revision of Portuguese building energy systems regulation.

- Some proposals for future legislation.

- Improvement of Portuguese buildings promoting energy efficiency.

\section{A R T I C L E I N F O}

\section{Article history:}

Received 31 December 2012

Received in revised form

21 September 2013

Accepted 8 November 2013

Available online 10 January 2014

Keywords:

Energy efficiency in buildings

Legislation and regulations

Lighting

Daylighting

Design of buildings and technical building systems

\begin{abstract}
A B S T R A C T
The behavior of building designers is conditioned by the existing legislation and regulations in the national context in which they operate. However, in the Portuguese legislation there are no rules concerning the use of daylight, and therefore, designers are not stimulated to adopt solutions that make use of the existing potential of sunlight availability. In the same way, it is difficult to understand the lack of specific regulation, with quantified targets, limiting power density of artificial lighting installed inside buildings. The present opportunity, generated by the need to carry out the revision of Portuguese building energy systems regulation, should be used to fill the existing gap in national legislation regarding those matters. In this paper the authors present some proposals for future legislation that will have as central purpose the utilization of efficient lighting systems and the promotion of architectural solutions that optimize the use of daylighting. It is possible, and desirable, to add new directives to national legislation that contribute to the improvement of Portuguese buildings, characterized by its good performance in terms of daylight availability, and at the same time, increasing the energy efficiency and reducing the energy consumption of lighting systems installed in those buildings.
\end{abstract}

(c) 2013 Elsevier Ltd. All rights reserved.

\section{Introduction}

One of the sectors with higher preponderance on Portuguese energy consumption is the building sector, both in its residential and commercial components, as can be seen in the statistics of energy consumption published over past years. This is the case of the year 2009 , more recent consolidated data, where energy consumption in buildings is $30 \%$ of total national consumption in final energy (DGEG, 2010) and approximately 60\% of national electricity consumption (INE, 2011). A substantial portion of that energy consumption is electrical energy used to generate artificial lighting in commercial buildings. With this present concern, and to illustrate numerically

\footnotetext{
* Corresponding author.

E-mail addresses: aalmeida@isec.pt (A.M. Almeida), agmartins@uc.pt (A.G. Martins).
}

the significance of lighting in energy consumption, it was possible to find a value for the rate of lighting energy consumption in the total electricity consumption of commercial buildings from the data published in the synthesis report "Caracterização Energética do Sector de Serviços" (DGE, 1994). Thus, energy consumption for lighting could be estimated at $29 \%$ of the total electricity consumption in commercial buildings for the year 1991. We present this value, although with reluctance for its antiquity, for the purpose of illustration of the difficulty in making an informed characterization with more recent data as it should be. The $29 \%$ figure is in line with the statistics for the nearby country of Spain that shows that for the year of 2010, 31.4\% of electricity was consumed in lighting in commercial buildings (IDEA, 2011). Despite this difficulty, one can say without hesitation that lighting is one major consumer of electricity when analyzing energy consumption in the buildings sector. With reference to the above data, we can see the relevance of energy consumption of lighting and thus the available potential for 
energy savings. It is possible and desirable to add, in the new Portuguese law, directives that contribute to the improvement of buildings that are constructed in Portugal, characterized by its good performance in terms of availability of daylight, and at the same time, increasing the energy efficiency of lighting systems installed in those buildings.

\section{Reference of the EU}

Reducing levels of consumption for lighting in the building sector should be a concern for legislators taking them to put into law the necessary regulations to encourage the best available quality design, and construction, of residential and commercial buildings so they can make better use of daylight without forgetting or harming the thermal characteristics of those buildings. This concern is in consonance with what was defined as purpose and objective in various plans and programs produced and published based on decisions of legislators at both the national and EU level. All this changing environment arises mainly from the need to comply with the EU directive on the energy performance of buildings (Energy Performance of Buildings Directive - EPBD), both in its original version of 2002 and in the reformulation of 2010. The EPBD, the buildings directive 2010/31/UE of May 19 of 2010, stipulates in its Article 1 the application of minimum requirements for the energy performance of technical building systems, when installed for the first time or when those are replaced or improved. Likewise integrates in its Article 2, in an explicit manner, the technical equipment for lighting as a component of the "technical building system" and also determines that the consumption on lighting have to be present in the calculation or measurements of the energy needed to satisfy the total demand, in order to evaluate the energy performance of that building. In its Annex I, relating to the methodology for the calculation of energy performance of buildings, the need to include in this methodology the lighting installation (mainly in the non-residential buildings) is referred. Annex I also establishes that "The methodology shall be laid down taking into consideration at least the following aspects: (...); (f) the design, positioning and orientation of the building, (...); (g) passive solar systems (...)" and "The positive influence of the following aspects shall, wherever relevant in the calculation, be taken into account: (...); (d) natural lighting (...)" (EPBD, 2010). Thus, the EPBD is a valuable ally for those who understand how important is the integration in the national legislation of regulatory provisions that have in mind the relevance of energy consumption from lighting systems and promotes its reduction by application of project practices in line with knowledge about energy efficiency in buildings. Also the use of daylighting due to integration at the design stage of the building of architectural solutions that promote the use of natural light should be encouraged, always in conjunction with the thermal part of the project to avoid unwanted heat gains.

\section{Portuguese legislation and European standards}

As can be seen by the EPBD, the characteristics of positioning, orientation and construction of buildings are very important for its energy performance, and for this reason a field of action that the legislators should not forget. However, daylighting is almost nonexisting in Portuguese legislation. It shows a nearly complete regulatory uncertainty about the design and construction of buildings with the purpose of maximizing the use of daylight, and at the same time, increasing the visual comfort of the occupants. Take the case of the latest legislation, published in April of 2006, on the issue of energy consumption in buildings. In all these regulations you cannot find a concrete determination for the promotion of daylighting. This is also the case in the Law no. 79/2006 approving the "Regulation of Energy Systems for Buildings Acclimatization RSECE", although its Article 1 establishes "The observance of the principles of rational use of energy and the use of materials and suitable technologies in all building energy systems, in the perspective of environmental sustainability" actually about lighting there is no reference to a single quantified measure for limiting the energy consumption (RSECE, 2006). The regulatory legislation for buildings of 2006 does not promote the decrease for the consumption needs in lighting, neither promotes the use of daylight or gives precise guidance on the use of efficient lighting systems. This difficulty in finding references to lighting in legislation is not a recent phenomenon. Already in Law no. 38382/1951 about the "General Regulation of Urban Construction - RGEU", and following revisions, the promotion of daylighting is reduced to good intentions. In that law, the only specific measure that encourages the use of daylight is a minimum for the ratio of window area per pavement area (WFR - Window to Floor Ratio). In Article 71 of that law, the design of openings to the outside with a WFR at least $10 \%$ is mandatory in most areas except for lobbies, toilets, storage and small corridors, (RGEU, 1951). This WFR value is very low and can lead to a very poor implementation of daylighting (Littlefair, 1999). It is easy to conclude for the low ambition established in RGEU for the efficient use of daylight in Portuguese buildings.

Concerning to artificial lighting, the will to reduce their energy consumption, regarding the lighting power density - LPD installed, manifests in reality with processes of intentions and recommendations with lack of ambition. It is known that the limitation of power density is a key element to achieve the reduction of energy consumption for lighting; however it is very difficult to find a regulatory reference with quantified objectives for that quantity at the national level. The most relevant references on energy efficiency can be found in the "Portuguese National Action Plan for Energy Efficiency - PNAEE" and in the European standard "EN15193: Energy performance of buildings - Energy requirements for lighting”. The European standard, because it is of compulsory publication in Portugal, here is associated with the Portuguese law. Considering the first case, the PNAEE, published as law in May 2008 by the Resolution no. 80/2008 which aims to, through an aggregator plan, establish energy efficiency measures in various sectors, in his Program no. 5 on energy efficiency systems in buildings, for the special case of commercial buildings, the objective of achieving "Regulations on lighting with a maximum of $\mathrm{W} / \mathrm{m}^{2}$ according to the uses" (PNAEE, 2008) with no reference to any measure or directive where we can envisage activities that will lead to that objective. Secondly, regarding the European standard EN15193, published in September 2007 and of mandatory adoption also in Portugal, the main objective is to define specifications for the calculation methodology for assessing the quantity of energy consumed on lighting inside buildings (EN15193, 2007). This standard also presents some schemes of reference for the objectives to be achieved on lighting energy consumption by setting references of good practices on lighting design, where it highlights the quantification of targets for the power density installed due to lighting equipment in relation to specific types of buildings. The values presented, for information purposes and not mandatory, have the particularity to their lack of ambition since, for the most part, they could easily be achieved through the installation of lighting systems based on conventional technologies, recognized for their poor performance and characterized by its energy inefficiency. One of the most interesting elements presented in EN15193 is the use of control factors in the calculation of the energy consumption per unit area for a year $\left(\mathrm{kWh} / \mathrm{m}^{2} /\right.$ year $)$. This calculation is based on an indicator called "Lighting Energy Numeric Indicator - LENI", which affects the LPD installed with a set of control factors that cause the reduction of 
power installed on the energy consumption estimation. When we calculate the LENI we are truly using reduced power densities for lighting as a function of a number of factors which are related directly to the types of control strategies to be used in the lighting control systems installed. In standard EN15193 are proposed three control factors (Fc - constant illuminance factor, Fd - daylight dependency factor and Fo - occupancy dependency factor) with direct influence on values of installed power to be used for the final calculation of the energy consumed per unit area per year. In a regulatory verification phase, with those factors, the electrical power of lighting systems installed in the building may be adjusted due to the existence of control and regulation capacity, leading to a decrease of the energy consumed used in the comparison with reference values.

\section{Situation in other countries}

Traditionally, the legislations of several countries determined a minimum value for the area of openings in facades, typically $10 \%$ of the respective floor area. It is the case of Portuguese legislation for residential buildings. However, the major concern that originated with this measure was to promote the public health of the occupants of the buildings and, to a lesser degree, to promote the use of natural light in those buildings. The WFR of $10 \%$ is insufficient if we aim to partially replace the need of artificial lighting with daylighting, in order to reduce the energy bill generated by lighting. One single definition of a minimum value for the area of openings to the outside opened the way for many buildings to be constructed with an oversizing of its glazed areas, causing serious problems of overheating due to excessive heat gains. In these cases, the decrease of energy consumption for lighting was undermined by the substantial increase in power requirements for cooling. The negative result in the rationalization of energy consumption due to excessive glazed area, led to the establishment of maximum values for the area of openings to the outside in the legislation of some countries. The key index used in that definition is the ratio of area of openings per area of facade (WWR - Window to Wall Ratio) which, through maximum levels, enables you to restrict the possibility of an unreasonable reduction in the area of the opaque facades, constructed based on thermal mass associated with insulation systems instead of surfaces more permeable to heat.

As regards the lighting installation, it is usual finding in legislation of several countries translation to the concern on limiting the electrical power installed in the spaces of buildings, especially by setting tables of maximum values for the lighting power density to be installed (in $\mathrm{W} / \mathrm{m}^{2}$ ) according to the type of use of the space. Another way to restrict excessive consumption of energy for lighting is materialized by setting benchmarks for the luminous efficacy of lighting systems (in $\mathrm{lm} / \mathrm{W}$ ) that must be met in each individual case of the building, which requires at the design stage the selection of equipment for generating artificial light with a good relation between the luminous flux emitted and the electrical power installed. The rational use of energy in lighting systems installed in buildings, based on the power density or the luminous efficacy of the light sources, can be related to daylighting through the definition of adjustment factors applied to the electrical power installed and, in this way, helping to promote the use of daylight. For instance, the use of control systems that include monitoring of the lighting conditions of the spaces with openings to the exterior can vary the permitted limit values for the electrical energy consumption in a given building space. In this way we can establish and encourage, even in an indirect way, the promotion of best practices for use of daylighting in buildings.
In order to illustrate all those issues, we present some of the solutions implemented in various regulations and those we found in consultation and review of the legislations of several countries, including Spain, France, United Kingdom (UK), United States of America (USA) and Australia. The results of our analysis were divided into three groups: daylighting measures, artificial lighting measures and daylight-linked lighting measures.

In the first set of measures, daylighting measures, are involved as key guidelines for the better design of the openings in the building envelope. As mentioned previously, the need to limit the area of the fenestration is a main concern in many countries laws, as can be seen in the case of UK (BR2000, 2010) and the USA (ASHRAE90.1, 2007) in which the WWR is limited to $40 \%$ and also in the Spanish case with the WWR limited to 60\% (CTE, 2009). However, the concern of allowing the entry of daylight with apertures greater than traditional levels of $10 \%$ of WFR can also be found, as shown in the French case with the definition of a minimum WFR of one sixth, approximately 17\% (RT2005, 2006). In the same context, the maximum limitations do not exclude the possibility of also limiting the WWR by a minimum, such as the case in UK with the notion that a space is only considered as naturally illuminated if it has a minimum of $20 \%$ WWR (HMG, 2010). This limit is proposed for glazing with values of light transmittance (Visible Light Transmittance - VLT) greater than $70 \%$, if the VLT is lower than $70 \%$ the WWR must be increased in accordance. In fact, the concern with the use of daylight has a greater practical implementation expressed in the legislation when it is associated with the project of the artificial lighting systems, mainly through adjustments in the values for the energy consumption used in the regulatory verification processes, a matter included in the third set of measures.

About the measures of the second set, those that have as their object the lighting systems and involve the need to reduce the electrical power installed using the best practices on project of efficient lighting systems for buildings, consist in the use of one of two different approaches but with common objectives. The first option, using the power density as reference, consists of comparing the watts per area unit installed due to the lighting equipment with density values of reference to be chosen depending on the type of utilization of space which are known in advance and properly tabulated. Among the countries that have chosen this approach are Spain, France, USA and Australia. In the Spanish case a set of values is defined for the power density per $100 \mathrm{~lx}$ and by type of use (for example office: $3.5 \mathrm{~W} / \mathrm{m}^{2} / 100 \mathrm{~lx}$ ), which are used as maximum reference after being weighted by the level of average illuminance at the work plane and for comparison with the power density installed in the building space (CTE, 2009). In the French case the reference values are independent of the level of illuminance at the work plane, up to $600 \mathrm{~lx}$, and they compare directly with the maximum LPD values determined from the type of use for the building (example for commercial buildings: $\left.12 \mathrm{~W} / \mathrm{m}^{2}\right)(\mathrm{RT} 2005,2006)$. In USA there are different procedures depending on the states. However both the federal department for energy as well as most states make sure as requirement for regulatory compliance, that the actual value of the installed power will not exceed the reference value for the maximum installed power calculated by the product of the area of spaces by the LPD of reference (example for office type: $11 \mathrm{~W} / \mathrm{m}^{2}$ ) (FR10CFR434, 2000). Australia adopted an equivalent method to the American case by comparing the installed power with a reference power, calculated from a reference value for the LPD found according to the type of use of the space (example office: $10 \mathrm{~W} / \mathrm{m}^{2}$ ) (BCA2009, 2009). In a second approach, chosen by the UK for example, the regulatory compliance is evaluated by comparing the luminous efficacy from the artificial lighting system to be installed in the building and the reference value for that efficacy depending on the type of use 
of that building (example for commercial buildings: $55 \mathrm{~lm} / \mathrm{W}$ ) (HMG, 2010).

In the third set of measures, designated as daylight-linked lighting measures, can be found the methods that apply adjustments to the values used in the comparisons between reference values and the projected values for energy consumption due to the existence of control in the lighting system of solutions that make use of information on the amount of daylight that enter into the spaces. These solutions are based on the common knowledge that the use of daylighting leads to a decrease in electricity consumption for lighting if it is accompanied by the inclusion in their control processes of automatic technologies of switching, regulating and load shedding based in information that is acquired from the monitoring of illuminances in the spaces. The change in the values used for comparisons in processes of regulatory verification, via use of daylighting and also via information about occupation of the spaces is present for example in legislations from the UK, USA and Australia. In UK the legislation defines a couple of numerical constants called "control factors" which are lower than unity and when applied to a division operation between the luminous efficacy of the lighting system installed and the value of the control factor result in increased performance of the installation when used in comparison with the reference value (example of control factor for commercial buildings with use of daylighting: 0.9). In USA sometimes numerical constants called "power adjust factors" are used, which act as lighting power credits, i.e., the effective value of installed power is reduced in a given percentage because there is automatic control and regulation of lighting based on information of the existence of daylight (example of power adjust factor for federal buildings with dimming control: 0.3 , a $30 \%$ reduction). Finally, in Australia "power density adjust factors" are defined which are used to increase the allowed power density in a given space of the building according to the type of use and to the control strategy to be implemented, i.e., the power density of reference for a particular situation will be divided by the corresponding adjustment factor resulting in an increase of the reference used in the regulatory compliance process (example of power density adjust factor for dynamic control based on daylight information: 0.5).

In fact, the size of the openings in the facades and the electrical power of the lighting systems are not the only concerns that are referenced in the legislation of the various countries under review. In all these legislations we can find references to recommendations and guidelines about the best practices for buildings design with the primary concern in lighting. Also, we can find proposals for the installation of control systems based on information obtained by monitoring illuminances and/or detection of occupants in spaces, information on how to segregate the control of the power supply circuits of light sources and how to coordinate the control of these circuits relatively to the openings with the gains of daylight.

\section{Efficient lighting, proposals}

From the overall results of the analysis of the national situation with the lessons learned from the study of solutions in the legislation of other countries, we can conclude that it is possible and desirable to join some of the determinations and guidelines to the Portuguese law that are essential to ensure the construction of better buildings in our country, characterized by their optimum performance in terms of available light, natural and artificial, and by the efficiency of all the lighting processes.

The most obvious way to allow the entry of daylight in spaces of buildings is to project and implement a correct fenestration in the building envelope. In that project one of the most significant aspects is the area of the windows. However, as already mentioned, the fenestration has implications not only in terms of daylight but also at a thermal level. One cannot increase the area of the windows in a very significant way since this would imply a very substantial increase of heat gains that would be undesirable in extended time periods throughout the year. In fact, values of WWR between $20 \%$ and $40 \%$ would correspond to a beneficial commitment between proper use of daylight and the avoidance of excessive heat gains through openings (ASHRAE, 2011). In Portuguese law it is possible to put a regulatory determination that requires the openings to outside have an area corresponding with at least $20 \%$ of WWR, without prejudice to the definition of special situations in which this is not mandatory. Even though without justification supported by daylight, the WWR should be limited to values lower than 40\% (NREL, 2010). Other proposals can also cover the definition of a recommended minimum value for the transmittance of glazing, for example with a VLT of $70 \%$ or greater, and the recommendation for the use of interior walls and ceilings with reflection coefficients of high values, for example greater than $75 \%$

Contrary to what happens today in Portugal, the legislation on buildings shall have a regulatory verification procedure on the viability of a building in relation to the levels of energy consumption due to lighting. As part of the verification process of regulatory conformity we propose a solution that combines the limitation of electrical power installed with the levels of illuminance at the work plane, for example, by defining limits to the LPD per $100 \mathrm{~lx}$. This index (LPD per $100 \mathrm{~lx}$ ) appeals to designers and installers and at the same time allows limiting the installed power, if the recommended minimum illuminance values presented in the EN12464-1 standard are followed. It would be desirable that in the new regulations the necessity to avoid excessive illuminances at the work plane is established, for example by setting maximum values for these illuminances according to a maximum increase of a small percentage of the value recommended in the standard. The regulatory verification through LPD per $100 \mathrm{~lx}$ is materialized by calculating a value limit for the density of installed power in relation to the average illuminance achieved and maintained at the level of the work plane, called "average maintained illuminance". The limit value for the LPD per 100 lx must be defined in accordance with the type of tasks to be performed in the spaces of the buildings. This requires the definition of different limit values according to those different types of utilization of the spaces. The definition of those values must take into account a set of information obtained from lighting professionals, the possibility of using control strategies with luminous flux regulation and/or occupant detection, and also the need to promote the concepts of efficient lighting. In some special situations where it can be demonstrated that the reference values are unfeasible by limitation of the equipment existing in the market, the regulatory values of LPD per $100 \mathrm{~lx}$ can be increased, pending on a corresponding justification, to ensure that the lighting system in question can be installed without compromising the regulatory verification of the entire building. In the verification phase of the regulatory conformity we can make adjustments in the values of LPD per $100 \mathrm{~lx}$ installed in the building due to the existence of capacity of control and regulation of luminaires, leading to a decrease in the values of installed LPD. These adjustments can be achieved by setting numerical constants, called control factors, which will be used to reduce the lighting power value used in the regulatory conformity verification procedures. The control factors, defined in terms of the control strategies to be adopted, are constants of proportionality that will lead to a decrease in the regulatory value of installed power of the lighting systems. The two automatic control strategies with more disseminated use in buildings are the control of lighting systems by use of information of the presence of 
occupants in the spaces (control for occupancy detection) and the continuous regulation of emitted luminous flux from the knowledge about the level of light present in those spaces (automatic dimming control). The control strategy with regulation of the luminous flux has more relevant application when linked to the use of daylight. The installation of these strategies and respective control systems should be mandatory in some types of uses of spaces in commercial buildings.

We can also promote daylighting by rewarding projects that have implemented in their lighting systems the control strategies with regulation of luminous flux, the monitoring of illuminances and use of daylighting. This stimulus can be materialized by the limited variation in the values of installed power to be used in regulatory verification procedures. For example, if a lighting system with a daylight-linked type of control can reduce consumption of electricity at very significant levels, exceeding $30 \%$ (Leslie et al., 2005), it is possible to promote their installation and, indirectly, the use of daylight, if we have the possibility of increasing the value of the electrical power to be installed. If we apply a dynamic control for reducing the artificial luminous flux when it is supplemented by daylight then it is possible to define one coefficient like control factor that is applied to reduce the value of installed power used in the verification process for the regulatory conformity, for example a $20 \%$ reduction on the initial value.

Other cases of rationalization corresponding to good design practices of artificial lighting systems can be referred:

- Electrical supply circuits of luminaires depending on their position relative to the openings in the facades and the distribution of activities in spaces must be correctly segregated.

- With automatic control, each distinct group of luminaires that share the same control signal, because they have the same functional specifications, should have its own sensorial information of illuminance.

- If the control of the supply power circuits has a manual component then the respective switches should be located within the space to be illuminated and with facilitated access.

\section{Conclusions}

Lighting in buildings has a relevance that, besides being intuitive, the share of energy consumption responsible can be recognized from the few known data. The few allusions to lighting in the legislation are, in most cases, statements with good intentions but without implementation of effective rules. This lack of specific regulations is not common in other countries. As we can see in the brief analysis of legislations of other countries presented in this paper, lighting is very much present not only in terms of objectives but with mandatory targets and quantified measures both for artificial lighting as well as for daylighting. These determinations are manifested mainly by limiting the consumption of electricity for lighting and by promoting the use of daylighting. In the first case, by setting maximum levels for energy consumption constrained by lighting power density values that promote the use of efficient lighting systems. Secondly, by encouraging the placing in architectural design of openings in the building envelope to allow the entrance of daylight, being complemented by lighting systems that use optimized control strategies in order to reduce the need for energy consumption. Lighting should appear in Portuguese legislation, about energy performance of buildings, whose relevance is already present in the energy bill of each building and, as a whole, in the country's energy consumption.

\section{References}

ASHRAE, American Society of Heating, Refrigerating and Air-Conditioning Engineers, 2011. Advanced Energy Design Guide for Small to Medium Office Buildings: Achieving 50\% Energy Savings Toward a Net Zero Energy Building. Design Guide edited by the American Society of Heating, Refrigerating and AirConditioning Engineers - ASHRAE, USA. ISBN 978-1-936504-05-3.

ASHRAE90.1, 2007. American National Standards Institute, ANSI/ASHRAE/IESNA Standard 90.1-2007. Energy Standard for Buildings Except Low-Rise Residential Buildings. American Standard prepared by the American Society of Heating Refrigerating and Air-Conditioning Engineers - ASHRAE, USA. ISSN: 1041-2336.

BCA2009, 2009. Department of Innovation, Industry, Science and Research. Building Code of Australia 2009, Building Regulations. Legislation prepared by the Australian Building Codes Board, Australia.

BR2000, 2010. The Stationery Office. The Building Regulations 2000, AD L2 Conservation of Fuel and Power in Buildings Other Than Dwellings, 2010 ed., Approved Document, UK.

CTE, 2009. Ministerio de Vivienda. Código Técnico de la Edificación, DB-HE: Ahorro de Energia. Spanish Legislation, Spain.

DGE, Direcção Geral de Energia - Ministério da Economia, 1994. Caracterização Energética do Sector de Serviços. Synthesis Report. Lisbon, Portugal. ISBN: 972 9030-77-4.

DGEG, Direcção Geral de Energia e Geologia - Ministério da Economia, 2010 Indicadores Energéticos - Quadro III (1990-2009). Portugal. XLS file from: 〈http://www.dgeg.pt〉.

EN15193, 2007. CEN - European Committee for Standardization. EN15193: Energy Performance of Buildings - Energy Requirements for Lighting. European Standard Ref. no. EN 15193:2007, Belgium.

EPBD, 2010. Parlamento Europeu e Conselho da União Europeia, Directiva 2010/31/ UE de 19 de Maio de 2010 relativa ao desempenho energético de edifícios. J. Off. União Eur. (PT), L153, (13) (European Union).

FR10CFR434, 2000. Department of Energy. Federal Register, 10 CFR Part 434, Energy Code for New Federal Commercial and Multi-Family High Rise Residential Buildings. Final Rule by the Office of Energy Efficiency and Renewable Energy DOE, USA.

HMG, HM Government, 2010. Non-Domestic Building Services Compliance Guide 2010 ed., NBS Document for the Building Regulations UK, UK.

IDEA, Instituto para la Diversificación y Ahorro de la Energia, 2011. Plan de Acción de Ahorro y Eficiencia Energética 2011-2020 -Anexo. Action Plan From the Spanish Government, Madrid, Spain.

INE, Instituto Nacional de Estatística, 2011. Indústria e Energia em Portugal 20082009. Official Statistics Publication, 2011 ed., Lisbon, Portugal. ISSN 2182-1836.

Leslie, R., et al., 2005. The potential of simplified concepts for daylight harvesting. Light. Res. Technol. (USA) 37 (1), 21-40.

Littlefair, Paul, 1999. Daylighting and Solar Control in the Building Regulations, Report Prepared by the Building Research Establishment - BRE, Watford, UK.

NREL, National Renewable Energy Laboratory, 2010. Technical Support Document: Strategies for 50\% Energy Savings in Large Office Buildings. Technical Report NREL/TP-550-49213, USA.

PNAEE, 2008. Presidência do Conselho de Ministros. Plano Nacional de Acção para a Eficiência Energética - Portugal Eficiência 2015. Resolução do Conselho de Ministros no. 80/2008. Diário da República no. 97: 2824-2865 - I Série-A de 20 de Maio de 2008. Portugal.

RGEU, 1951. Ministério das Obras Públicas. Regulamento Geral das Edificações Urbanas. Decreto-Lei no. 38382/51 de 7 de Agosto de 1951, Portugal.

RSECE, 2006. Ministério das Obras Públicas, Transportes e Comunicações. Regulamento dos Sistemas Energéticos de Climatização em Edifícios (RSECE). DecretoLei no. 79/2006. Diário da República no. 67: 2416-2468 - I Série-A de 4 de Abril de 2006, Portugal.

RT2005, 2006. Ministère de L'Emploi, de la cohésion sociale et du logement. Réglementation thermique 2005 - arrêté relatif aux caractéristiques thermiques des bâtiments nouveaux et dês parties nouvelles de bâtiments]. Off. Repub. Fr. (France) 14 (155), art. 32. 